\title{
Effectiveness of a parental school-based intervention to improve young children's eating patterns: a pilot study
}

\author{
Ana Isabel Gomes*, Luisa Barros, Ana Isabel Pereira and Magda Sofia Roberto \\ Faculty of Psychology, University of Lisbon, Alameda da Universidade, 1649-013 Lisbon, Portugal
}

Submitted 15 August 2017: Final revision received 11 March 2018: Accepted 16 March 2018; First published online 23 April 2018

\begin{abstract}
Objective: To evaluate the effectiveness of a pilot study of a parental school-based intervention to promote healthy eating behaviours in young children.

Design: A quasi-experimental longitudinal design with three conditions (complete intervention (CIG), minimal intervention (MIG), control (CG)), with repeated measures at baseline, immediately after the intervention, 6 months and 1 year after intervention.

Setting: Fourteen public and state-funded kindergartens near Lisbon, Portugal.

Subjects: Parents ( $n$ 349) of 3- to 6-year-old children assigned to the three conditions completed the baseline protocol. The 'Red Apple' intervention included four parental group sessions about young children's growth, nutritional guidelines and positive parental feeding strategies, which was combined with adult-child activities at home and in the classroom, and newsletters (CIG). MIG included only a single nutritional counselling session, whereas the CG had no intervention. At the end, thirty-eight, twenty-six and fifty-four parents in the CIG, MIG and CG, respectively, had completed all evaluation components. Data regarding parental perception of children's weight, self-efficacy, nutritional knowledge, feeding strategies, eating behaviours and BMI were collected at the four assessment moments.

Results: The CIG showed improvements in children's healthy food intake, compared with the MIG and CG. Parental self-efficacy regarding the regulation of children's eating behaviours decreased in the CG but not in both intervention groups.

Conclusions: Considering the low dosage of the intervention, the results obtained were positive. Future studies should offer additional solutions to overcome barriers to parents' participation.
\end{abstract}

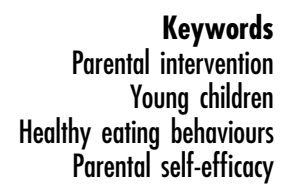

Early childhood overweight has been progressively recognized as a public health problem, with systematic reviews reporting rates of excessive weight of up to one-third in children and adolescents ${ }^{(1,2)}$. In Portuguese samples, the prevalence of overweight in young children reaches similar values $^{(3,4)}$. The development and implementation of comprehensive programmes that positively impact early childhood weight- and obesity-related behaviours is crucial. The first years of life have been acknowledged as an exceptional period for intervention on healthy eating promotion and obesity prevention ${ }^{(5)}$. BMI undergoes important changes between 4 and 6 years of age, constituting one of the three critical periods for the development of overweight $^{(6)}$. Consequently, this period offers a major opportunity to keep the child's growth on a healthy trajectory $^{(7)}$. Moreover, there is extensive evidence that eating patterns and food preferences are acquired during these years and are shaped by early experiences with foods and flavours ${ }^{(8,9)}$. Energy balance-related behaviours, psychological traits and physiological processes can be optimally influenced at this age ${ }^{(10)}$ since children's high plasticity and rapid transitions occur concurrently with adults' primary control over children's environment and interactions $^{(11)}$.

The Commission on Ending Childhood Obesity recommended that interventions to prevent childhood overweight should provide guidance to parents and caregivers on children's healthy body size and age-appropriate nutrition, to decrease portion size, limit the consumption of energy-dense and nutrient-poor foods, and encourage the intake of a wide variety of fruits and vegetables ${ }^{(12)}$. School- and family-based interventions can lead to positive changes in pre-school children's diet and slightly improve weight outcomes ${ }^{(13)}$. Programmes that include parents as key targets and agents of change, combining parental involvement with behavioural interventions and not focusing only on nutritional education, are more likely to be successful in providing effective and long-lasting 
changes in children's eating patterns ${ }^{(14-17)}$. The involvement of kindergartens can optimize the long-term effectiveness of interventions for children's healthy food intake ${ }^{(18,19)}$ and allow easier access to children and parents from mixed socio-economic backgrounds ${ }^{(10)}$.

Parental cognitive dimensions have been related to parents' motivation to implement strategies to regulate their child's food intake. Traditionally, interventions developed to target healthy eating behaviour have included, as a main parental cognitive outcome, nutrition and/or diet knowledge $^{(20,21)}$. However, targeting other cognitive dimensions may contribute to parental change. Parent report of higher self-efficacy to promote children's healthy diet has been associated with young children's higher consumption of vegetables and fruits and lower intake of sugary foods ${ }^{(22)}$. On the other hand, early parental identification of the child's physical signs of overweight ${ }^{(23)}$ and recognition of their child's weight as a health problem ${ }^{(24)}$ seem to be related to parents' readiness to improve the family's diet quality and effectively manage the child's eating. However, how these dimensions change over time or in response to parental education programmes remains unclear. Only a few intervention studies that involved parents of pre-school children measured parental self-efficacy at follow-up and change in parental perception of their child's weight has not been reported as an outcome measure ${ }^{(17,20,25)}$.

The purpose of the present study was to conduct a pilot test of the effectiveness of the 'Red Apple' programme, a brief parental school-based intervention to promote healthy eating behaviours in their young children, and to assess the impact of the programme on behavioural measures (child's healthy and unhealthy eating habits, parental feeding practices) and parental cognitive dimensions previously associated with parents' motivation to engage in positive changes related to the child's eating patterns (i.e. parents' perception of the child's weight, self-efficacy and nutritional knowledge). We hypothesized that the 'Red Apple' programme, compared with a single parental nutrition education session and a control condition with no intervention, would result in: (i) a significant increase in the child's healthy food intake and a decrease in the child's unhealthy food intake; (ii) improved parental self-efficacy, nutritional knowledge and feeding practices; and (iii) a more accurate parental perception of the child's weight. It was also expected that these changes would continue, at least partially, during follow-up.

\section{Methods}

\section{Study design}

The present study used a quasi-experimental, longitudinal design with three conditions (complete intervention (CIG), minimal intervention (MIG), control (CG)) and four repeated measures (at baseline, immediately after the intervention, 6 months and 1 year after the intervention).

\section{Participants}

Detailed information about the participants in the study can be found in Fig. 1. Of the initial 743 parents invited, 353 returned the evaluation protocol. Four parents were considered ineligible for analysis. After this process, 138 parents were assigned to the CIG, 120 were assigned to the MIG and ninety-one were assigned to the CG. At the end of the study, thirty-eight parents in the CIG, twenty-six parents in the MIG and fifty-four parents in the CG had completed all the evaluation components.

Table 1 presents sociodemographic and clinical variables for the three groups at baseline. Most questionnaires were completed by mothers (100\% for CIG, $92.3 \%$ for MIG, $96.3 \%$ for CG). In general, children lived with both parents and most were 4 or 5 years old $(73.7 \%$ for $\mathrm{CIG}, 73.1 \%$ for MIG, $92.6 \%$ for CG). There was a similar percentage of boys and girls in the sample.

\section{Instruments}

Sociodemographic and clinical information

Background information about children's age, gender, gestational age at birth and chronic health conditions, parent's age, kinship with the child, family composition and educational level was collected using a general questionnaire.

\section{Parent's perception about the child's current weight (correct/incorrect)}

Parents were asked to subjectively rate their child's current weight, considering the child's age and height ('underweight', 'average weight', 'overweight'). The Centers for Disease Control and Prevention's standards were used to calculate BMI-for-age percentiles (boys and girls) and nutritional status, because, at the time of the study, these charts were still being used by Portuguese physicians (WHO charts only started to be used at consultations with children born after March 2014). Children above the 85th percentile were classified as overweight, those below the 5th percentile as underweight and the remaining children as healthy weight. Parents' perception of children's weight was then compared with children's nutritional status and categorized as correct or incorrect $^{(26)}$.

\section{Parent's self-efficacy}

A short questionnaire with four items was developed to evaluate parents' perception of their efficacy in promoting their children's healthy food intake (e.g. 'To what extent am I sure that I can get my child to have a healthy diet?'), controlling the intake of unhealthy foods (e.g. "To what extent am I sure I am able to control the behaviour of my child, so that he/she does not eat too much candy?'). The scale was developed according to the objectives of the intervention and general guidelines for the self-efficacy scale construction $^{(27)}$ and was submitted to a validity and reliability analysis. For each item, parents answered on a 


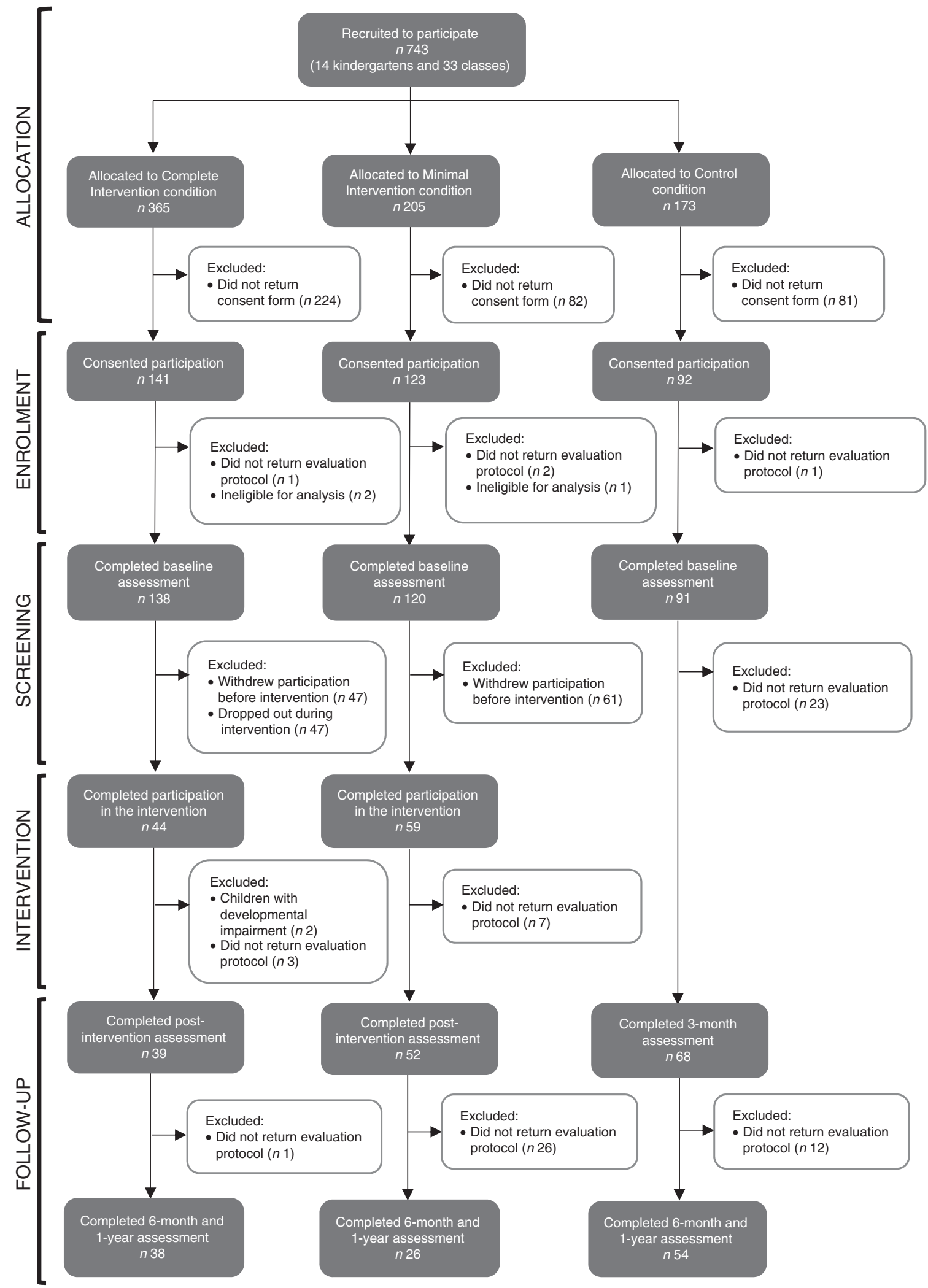

Fig. 1 Flow of the participants through the pilot study of the 'Red Apple' programme, a parental school-based intervention to promote healthy eating behaviours in young children (aged 3-6 years), Lisbon, Portugal, October 2011-June 2014

5-point Likert scale; the responses were summed to calculate the total score, with higher values indicating higher self-efficacy (score ranged between 4 and 20). This scale showed acceptable internal consistency $(\alpha=0.74$; mean inter-item correlation $=0.35)$ and good test-retest $(15 \mathrm{~d}$ interval) reliability $\left(r_{\mathrm{s}}=0 \cdot 78, P>0 \cdot 01\right)$. 
Table 1 Sociodemographic and clinical variables for the three group conditions at baseline in the pilot study of the 'Red Apple' programme, a parental school-based intervention to promote healthy eating behaviours in young children (aged 3-6 years), Lisbon, Portugal, October 2011-June 2014

\begin{tabular}{|c|c|c|c|c|c|c|}
\hline \multirow[b]{3}{*}{ Variable } & \multicolumn{6}{|c|}{ Group condition } \\
\hline & \multicolumn{2}{|c|}{ CIG $(n 38)$} & \multicolumn{2}{|c|}{ MIG (n 26) } & \multicolumn{2}{|c|}{ CG $(n 54)$} \\
\hline & $n$ & $\%$ & $n$ & $\%$ & $n$ & $\%$ \\
\hline \multicolumn{7}{|l|}{ Parent's age (years) } \\
\hline $25-44$ & 34 & 89.5 & 25 & $96 \cdot 2$ & 52 & $96 \cdot 3$ \\
\hline$>45$ & 4 & $10 \cdot 5$ & 1 & 3.8 & 2 & 3.7 \\
\hline \multicolumn{7}{|l|}{ Parent's educational level (years) } \\
\hline Elementary school & 3 & 7.9 & 4 & $15 \cdot 4$ & 8 & $15 \cdot 1$ \\
\hline Secondary school & 12 & $31 \cdot 6$ & 11 & $42 \cdot 3$ & 16 & $30 \cdot 2$ \\
\hline College education & 23 & $60 \cdot 5$ & 11 & $42 \cdot 3$ & 29 & 54.7 \\
\hline \multicolumn{7}{|l|}{ Household situation } \\
\hline Both parents & 36 & 94.7 & 23 & 88.5 & 48 & 88.9 \\
\hline Mother & 2 & $5 \cdot 3$ & 2 & $7 \cdot 7$ & 6 & $11 \cdot 1$ \\
\hline Father & 0 & 0 & 1 & $3 \cdot 8$ & 0 & 0 \\
\hline Parent's report of child's chronic health conditions & 4 & 10.5 & 2 & $7 \cdot 7$ & 4 & $7 \cdot 4$ \\
\hline Child's gestational age at birth (preterm) & 4 & 10.5 & 2 & $7 \cdot 7$ & 1 & 1.9 \\
\hline
\end{tabular}

CIG, complete intervention; MIG, minimal intervention; CG, control.

\section{Parent's nutritional knowledge questionnaire}

The questionnaire on parent's nutritional knowledge ${ }^{(28)}$ contains ten items describing beliefs about pre-school children's diet and eating behaviours that were chosen originally by researchers and health professionals working with parents of young children in dietary consultations. Parents answered on a 5-point Likert scale ('right', 'I think it is right', 'I do not know', 'I think it is wrong', 'wrong'). Correct responses were scored as +2 if the parent was sure about the answer and +1 if $s /$ he was unsure; incorrect answers were scored as -2 or -1 depending also on the parent being sure or not about the answer, and 'I do not know' as 0, with a higher total score indicating better nutritional knowledge. The Portuguese version was subject to preliminary analysis, based on difficulty and discrimination indices calculation, and eight items were considered for the total score (score ranged between -16 and 16$)$. Test-retest ( $15 \mathrm{~d}$ interval) reliability was good $\left(r_{\mathrm{s}}=0 \cdot 88, P<0 \cdot 01\right)$.

\section{Children's Eating Habits Questionnaire}

The Children's Eating Habits Questionnaire (CEHQ) was developed to assess the quality of the children's dietary habits, based on national and international dietary guidelines for young children. Although recognizing the limitations of this kind of measure, the option for an FFQ aimed to better adapt the assessment to the specific objectives of the intervention, to cover a larger time frame and to target the usual eating patterns of the child. This instrument was developed in collaboration with a group of dietitians and a validity and reliability analysis was conducted to confirm its sensibility to change ${ }^{(29)}$. Parents' report of children's frequency of consumption of several foods was evaluated on a 4-point Likert scale ('never', '1-2 times a week', '3-6 times a week', 'every day'). After an exploratory factor analysis, the items were grouped into two dimensions: healthy foods (soup, fruits, vegetables and fish) and unhealthy foods (desserts, candies, fast foods, sodas and foods with added salt/sugar). Higher mean values on the total score of the scales corresponded to more frequent intake of those foods (score ranged between 1 and 4 for both scales). Details about the conception of the instrument and psychometric features are described elsewhere ${ }^{(30)}$.

\section{Caregiver's feeding styles questionnaire}

The nineteen-item caregiver's feeding styles questionnaire ${ }^{(31)}$ evaluates parental feeding styles through a 5-point Likert scale, in which parents indicate the frequency of use of specific strategies. For the Portuguese version, a sequence of exploratory factor analyses was run, which resulted in the extraction of two factors: coercive (parent-centred strategies used to modify the child's eating behaviours through disapproval, pressure to eat, physical punishment and contingency management; ten items) and inductive (child-centred strategies based on reasoning, positive reinforcement and child's involvement in decisions about food; seven items). The answers for each subscale were summed, with higher values indicating a more frequent use of each group of strategies (total score ranged between 10 and 50 for coercive strategies, between 7 and 35 for inductive strategies). The scales achieved good and acceptable internal consistency (coercive strategies $\alpha=0.87$; inductive strategies $\alpha=0.69$; mean inter-item correlation $>0.2$ for both scales) and good test-retest ( $15 \mathrm{~d}$ interval) reliability $\left(r_{\mathrm{s}}=0.84, P<0.01\right.$ and $r_{\mathrm{s}}=0.78, P<0.01$ for coercive and inductive strategies, respectively).

\section{Procedure}

Recruitment and data collection were performed between October 2011 and June 2014. Fourteen public and statefunded kindergartens near Lisbon were invited and agreed to participate in the study. Schools were randomly allocated to one of the three conditions, so that in each school 
all participants were in the same group, to control for possible dissemination of information. Acknowledging earlier reports of high rates of attrition in childhood obesity prevention programmes, approximately twice the number of participants in the CG were attributed to the CIG. Recruitment occurred simultaneously for the three conditions at four times during the year, to account for the possible influences of seasons and festivities in the children's eating behaviours. Parents were invited to participate through a leaflet sent home; those who agreed received the informed consent and the evaluation protocol through the kindergarten teacher, with instructions for completion and to return the questionnaires in sealed envelopes. After parents' enrolment, children's weight and height measurements were assessed in the school by a dietitian with experience in anthropometric evaluations in infancy. Children were individually taken to a separate room, where they were weighed and measured in light clothing and without shoes before lunch, with a SECA ${ }^{\circledR}$ model 220 column scale with stadiometer.

\section{Complete intervention group: 'Red Apple' programme}

The 'Red Apple' programme was inspired by cognitive and social-cognitive theories, and intervention goals were selected considering the dimensions commonly considered as determinants of behavioural intentions and behaviour itself, namely threat appraisal (severity, vulnerability), self-efficacy and behavioural control (internal control factors as skills and information; external control factors as barriers and opportunities $)^{(32,33)}$. Thus, we developed an intervention aimed at modifying the specific parental cognitive determinants known to be related to the child's eating behaviour and/or the parent's motivation to undertake changes in diet (perception about the child's weight, self-efficacy and nutritional knowledge $)^{(21,34,35)}$, to influence parental attitudes and practices according to the individual characteristics of their child and thus modify children's dietary intake.

The 'Red Apple' programme included four sessions, each focusing on one major theme related to the young child's growth process, nutritional guidelines and parental strategies to promote children's healthy eating behaviours (Table 2). The approach was behaviourally focused, promoting the participation of the parents and supported by everyday examples. At the end of each session, a themerelated homework assignment was proposed, suggesting adult-child activities between sessions to apply the strategies discussed in the session and inviting caregivers to reflect on the benefits of applying the suggested changes. A week after each session, parents received a newsletter, reinforcing the key messages of the previous session. The intervention was delivered to fourteen groups, each one with six to eight parents. Sessions were conducted in the schools in the presence of the class teacher and were scheduled to better fit parents' preferences, which were previously assessed in the baseline protocol. Each session lasted $90 \mathrm{~min}$ and occurred every two weeks. The first author was responsible for the delivery of the intervention, with the participation of a dietitian in the second session to direct the nutritional education component. Only those parents who participated in the first two sessions and in at least one of the sessions dedicated to parental feeding strategies were considered to have completed the programme and were retained for statistical analysis.

\section{Minimal intervention and control groups}

Parents assigned to the MIG attended only a nutritional counselling session with the dietitian (similar to the second session in the CIG) and received the homework assignment and a newsletter related to the theme. We chose different dosages for the two intervention condition groups because our aim was to assess the benefits of a comprehensive intervention targeting cognitive parental variables beyond nutritional knowledge, compared with a single healthy eating sensitization session, most often provided in Portuguese kindergartens. Parents included in the CG did not receive any intervention and completed the evaluation protocol.

\section{Process evaluation}

Fidelity to intervention delivery was evaluated through recording of the activities performed by the facilitator during the sessions and the homework assignments returned by parents and kindergarten teachers along the programme. Parental satisfaction regarding the 'Red Apple' programme was evaluated separately through questions about utility and interest of the sessions, home activities, class activities and newsletters.

\section{Data analysis}

Initial statistical analyses were performed using the statistical software package IBM SPSS Statistics for Windows, version 23.0. The $\chi^{2}$ test and ANOVA were used to compare samples in the three conditions on nominal and ordinal variables (parental perception of children's weight, demographic and clinical variables) and metric variables (children's eating habits), respectively, after screening and before intervention. Similarly, differences between those who completed the intervention and those who dropped out were calculated using $\chi^{2}$ tests and independentsamples $t$ tests (or independent-samples Mann-Whitney $U$ tests as a non-parametric alternative). Mixed withinbetween ANOVA and Cochran's $Q$ tests (repeated measures) were conducted to compare the mean differences between conditions at each assessment point and between the four assessment moments in each condition.

\section{Results}

\section{Retention and dropout}

The retention rate for completion of the 'Red Apple' programme was $31.9 \%$. Several reasons were reported for 
Table 2 'Red Apple' intervention: structure and content of sessions

Session Theme

$1 \quad$ Child's growth process, nutritio and health

Objectives

Identify and discuss parental beliefs about children's growth and expectations about the possible consequences for health and development

Enhance parental awareness about physical signs of the normal and abnormal child growth process, as well as signs of excessive weight and risks associated

Reinforce parental responsibility in providing positive changes in the child's eating habits and growth

Healthy eating during Increase parental knowledge of specific nutritional pre-school years guidelines for a healthy diet in pre-school children Motivate parents to identify and implement
changes in the child's eating patterns

Parental strategies to Increase parental knowledge of the developmental promote healthy eating behaviours (Part 1) competencies of pre-school children

Help parents to reflect on how pre-school children's specific abilities to understand, think and learn abo nutrition can be used to influence messages about food and strategies to promote children's healthy eating behaviours

Encourage parents to implement dietary and behaviou changes according to age-appropriate strategies

Parental strategies to Enhance parental acknowledge of the benefits and promote healthy

(Part 2) efficacy of inductive feeding practices in the promotion of healthy eating behaviours in pre-school children.

Encourage parents to identify their main parenting feeding strategies and promote changes to a more inductive approach
Intervention content

Homework

Information about the consequences

Identification of the signs of the normal and abnormal

(excessive weight) child growth process in silhouettes Demonstration of the procedures to calculate children's $\mathrm{BMI}$ and percentile in growth charts, as well as understand their meaning

Group discussion about beliefs and myths regarding children's growth and parents' role as mediators of a child's healthy nutrition and development

Information about: (i) criteria for a healthy diet; (ii) the five food groups and main nutrients; (iii) specific portions appropriate for pre-school children; (iv) percentage of sugar found in unhealthy foods (e.g. sodas, cereals); (v) the importance of consuming at least five meals per day; (vi) the distribution of foods on the plate; (vii) healthy cooking; (viii) reading food labels

Group discussion about the role parents play in the choice, availability and preparation of foods for the family

Information about pre-school children's development: what should be expected of pre-school children physically and intellectually? (e.g. acquisition of gross and fine motor skills, prescientific concepts, health and illness concepts)

Information about pre-school children's interactions with food (e.g. ability to regulate the appetite and to understand satiety cues, development of food preferences and neophobia)

Group discussion about the most suitable strategies to promote healthy behaviours in this developmental stage (e.g. interactive, concrete, hands-on activitie with food using the senses; early learning experiences using a variety of foods, flavours and colours; procedures to exposure children to new oods, help offered to children to recognize interna signs of satiety, help offered to children to interpret

Information about inductive feeding practices (e.g. (o establish limits eating choices, modelling and 'do as I do' approach, positive reinforment, mealtimes and feeding environment food accessibility) Group discussion to analyse practical examples of child-food-parent interaction and best strategie strategies (e what to do when the child refuses a specific food, shows loss of appetite asks for an extra portion, asks for unhealthy items during shopping)
At home: Observe the child during the bath and/or compare the child's physical appearance through photographs from different stages for identification of physical signs of growth. Calculate the child's BMI and percentile according to age and gender growth charts.

In the class: 'Magic ruler: How tall I am?

At home: Observe the child's meals, identify aspects that need to be changed and provide meals according to nutrition guidelines for pre-school children.

Experiment with healthy and appealing recipes

In the class: 'Green sign for healthy eating!'; 'Let's make our food wheel!'

At home: Introduce new foods according to children's previous experiences and implement specific

strategies to attenuate neophobia. Promote children's food experiences through colours (e.g. choose foods of a specific colour for a meal). 'Belly training' to help children become aware of internal cues of satiety and hunger, and promote positive decisions about food consumption

the class: 'Green sign for healthy eating!'; 'Mystery food: let's taste, touch and smell to discover'; songs and stories about foods

At home: Identify parents' usual reactions towards the child's more challenging eating behaviours and introduce changes towards more inductive parental feeding practices. Observe routines about food preparation and cooking, mealtimes and feeding pent, and introduce relevant changes

'Artuss: 'Kindergarten teacher as a role model!' 'Artwork using the food wheel'; songs and about foods 
dropping out: incompatibility between programme sessions and work schedule (35.3\%), illness (23.5\%) and lack of childcare (11.8\%). For most variables, no significant differences were found between parents who completed the 'Red Apple' programme and those who dropped out. However, the parents who completed the intervention were younger $\left(\chi_{(4)}^{2}=9.611, \quad P=0.048\right)$, had more years of schooling $\left(\chi_{(4)}^{2}=12 \cdot 101, \quad P=0.017\right)$ and had children in the programme who were more likely to be preterm $\left(\chi_{(4)}^{2}=16.423, P=0.003\right)$.

For the MIG, the retention rate was higher (49.2\%). Parents who completed the nutritional session had a higher education level $\left(\chi_{(2)}^{2}=11 \cdot 849, P=0.003\right)$, and their children consumed fewer unhealthy foods $(U=1179 \cdot 5, P=0 \cdot 005)$ and had a higher BMI percentile $(U=1355, P=0 \cdot 049)$ than those who were enrolled but did not participate.

\section{Sample characteristics and group equivalence at baseline}

Table 3 reports the results of the variables at baseline for the parents who remained in the study and performed the four evaluation assessments. A considerable percentage of parents ( $26 \cdot 3 \%$ of CIG, $42.3 \%$ of MIG, $40 \cdot 7 \%$ of CG) failed to correctly recognize their child's weight status, with most underestimating the child's weight (90.0\% for CIG, 100.0\% for MIG, $95.5 \%$ for CG). The proportion of children with excessive weight was high (26.3\% for CIG, 34.6\% for MIG, $33.3 \%$ for CG).

At baseline, no significant differences were found among the three groups for the variables above (correct perception of child's weight: $\chi_{(2)}^{2}=2.499, \quad P=0.287$; child's weight: $\chi_{(4)}^{2}=2.443, P=0.655$; parents' self-efficacy: $F_{(2,115)}=0.139$, $P=0.870$; nutritional knowledge: $F_{(2,115)}=0 \cdot 139, \quad P=0 \cdot 870$; inductive strategies: $\quad F_{(2,115)}=0.208, \quad P=0.813$; coercive strategies: $F_{(2,115)}=0.006, \quad P=0.994$; healthy food intake: $F_{(2,115)}=0.884, P=0.416$; unhealthy food intake: $F_{(2,113)}=0.022$, $P=0.978)$.

Similarly, the demographic and clinical characteristics (see Table 1) of the samples at baseline did not differ significantly among the groups (parent's age: $\chi_{(2)}^{2}=2 \cdot 121$, $P=0.346$; parent's educational level: $\chi_{(4)}^{2}=2.852, P=0.583$; household situation: $\chi_{(4)}^{2}=4.565, \quad P=0.335$; child's age: $\chi_{(8)}^{2}=12 \cdot 743, P=0 \cdot 121$; child's sex: $\chi_{(2)}^{2}=0 \cdot 262, P=0.877$; child's gestational age at birth: $\chi_{(2)}^{2}=3 \cdot 193, P=0 \cdot 203$; child's health chronic problems: $\left.\chi_{(2)}^{2}=0 \cdot 306, P=0.858\right)$.

\section{Intervention effects}

Based on the results of the repeated-measures ANOVA for children's intake of healthy food, Mauchly's test indicated that the assumption of sphericity had been violated $\left(\chi_{(5)}^{2}=24.573\right.$, $P<0.001)$; therefore, degrees of freedom were corrected using Greenhouse-Geisser estimates of sphericity $(\varepsilon=0 \cdot 87)$. Significant effects were found for the condition $\times$ time interaction (within-subjects effects, $F_{(5,214 ; 297 \cdot 184)}=2 \cdot 370, P=0 \cdot 037$, $\eta_{\mathrm{p}}^{2}=0.040$ ) and condition (between-subjects effects, $\left.F_{(2 ; 114)}=5.722, P=0.004, \eta_{\mathrm{p}}^{2}=0.091\right)$. Further post boc analysis revealed that there were significant differences between baseline and post-intervention assessments for the CIG $(P=0 \cdot 004)$, suggesting a significant increase in the frequency of children's healthy food intake after the 'Red Apple' intervention. For the MIG, a significant decrease was found in the frequency of children's healthy food intake at the 6-month assessment compared with the post-intervention assessment $(P=0 \cdot 046)$. The CIG differed significantly from the other groups in each follow-up assessment, with higher values for children's healthy food intake (post-intervention: CIG $v$. MIG, $P=0.028$ and CIG $v$. CG, $P=0.000$; 6-month assessment: CIG $v$. MIG, $P=0.014$ and CIG $v$. CG, $P=0.026$; 1 -year assessment: CIG $v$. MIG, $P=0.028$ and CIG $v$. MIG, $P=0.017$ ).

The same statistical procedure showed a statistically significant effect of the condition $\times$ time interaction on parental self-efficacy (within-subjects effects, $F_{(6,342)}=2 \cdot 877$, $\left.P=0.010, \eta_{\mathrm{p}}^{2}=0 \cdot 048\right)$. In the CG, the baseline assessment differed significantly from the post-intervention $(P=0.027)$ and 1-year assessments $(P=0 \cdot 010)$, indicating that there was a significant decrease in parental self-efficacy at both followup evaluation points for this group compared with that at the baseline assessment.

No significant results regarding the effect of the condition $\times$ time interaction were found for the other metric variables examined (unhealthy eating habits: $F_{(5,605 ; 313,906)}=0.757, P=0.596, \eta_{\mathrm{p}}^{2}=0.013$; coercive strategies: $F_{(5,492 ; 302,064)}=0.247, P=0.952, \eta_{\mathrm{p}}^{2}=0.004$; inductive strategies: $\quad F_{(6 ; 333)}=1 \cdot 184, \quad P=0.314, \quad \eta_{\mathrm{p}}^{2}=0.021$; nutritional knowledge: $\quad F_{(6 ; 339)}=0.583, \quad P=0.744$, $\eta_{\mathrm{p}}^{2}=0 \cdot 010$ ). The proportion of parents in each group with a correct perception of their children's weight did not differ over time (CIG: $\chi_{(3)}^{2}=1 \cdot 723, P=0 \cdot 632$; MIG: $\chi_{(3)}^{2}=2 \cdot 118$, $P=0.548$; CG: $\left.\chi_{(3)}^{2}=1.723, P=0.632\right)$.

\section{Process evaluation}

At least sixteen of the eighteen activities that were designed to be accomplished throughout the 'Red Apple' sessions were delivered for all the groups. Homework assignments were completed by at least $70 \%$ of parents and $85 \%$ of teachers in all sessions. More than $90 \%$ of parents reported that each component of the programme was useful/very useful for changing their child's eating behaviours and interesting/very interesting in terms of knowledge transmitted and tasks proposed.

\section{Discussion}

The main objective of the present study was to conduct a pilot study to evaluate the effectiveness of a brief parental school-based intervention to promote young children's healthy eating behaviours, particularly its impact on specific behavioural (children's healthy and unhealthy eating habits, parental feeding practices) and cognitive variables (parents' perception of the child's weight, self-efficacy and nutritional knowledge). 


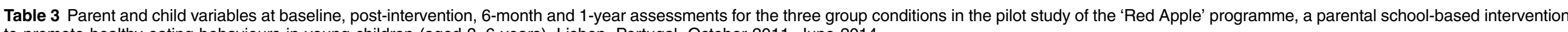
to promote healthy eating behaviours in young children (aged 3-6 years), Lisbon, Portugal, October 2011-June 2014

\begin{tabular}{|c|c|c|c|c|c|c|c|c|c|c|c|c|c|c|c|c|c|c|c|c|c|c|c|c|c|c|c|c|c|c|}
\hline \multirow[b]{4}{*}{ Variable } & \multicolumn{30}{|c|}{ Group condition } \\
\hline & \multicolumn{10}{|c|}{ CIG $(n 38)$} & \multicolumn{10}{|c|}{ MIG $(n$ 26) } & \multicolumn{10}{|c|}{ CG $(n 54)$} \\
\hline & \multicolumn{2}{|c|}{ Baseline } & \multicolumn{2}{|c|}{ Post-intervention } & \multicolumn{3}{|c|}{6 months } & \multicolumn{3}{|c|}{1 year } & \multicolumn{3}{|c|}{ Baseline } & \multicolumn{2}{|c|}{$\begin{array}{c}\text { Post- } \\
\text { intervention }\end{array}$} & \multicolumn{2}{|c|}{6 months } & \multicolumn{3}{|c|}{1 year } & \multicolumn{2}{|c|}{ Baseline } & \multicolumn{3}{|c|}{ Post-intervention } & \multicolumn{2}{|c|}{6 months } & \multicolumn{3}{|c|}{1 year } \\
\hline & Mean & SD & Mean & SD & Mean & SD & & Mean & SD & & Mean & SD & & Mean & SD & Mean & SD & Mean & SD & & Mean & SD & Mean & SD & & Mean & SD & Mean & SD & \\
\hline Self-efficacy & $15 \cdot 21$ & $2.12 \mathrm{~A}$ & $15 \cdot 79$ & $1.60 \begin{array}{l}\mathrm{a} \\
\mathrm{A}\end{array}$ & 15.68 & 1.83 & $\begin{array}{l}\mathrm{a} \\
\mathrm{A}\end{array}$ & 15.53 & 1.47 & $\begin{array}{l}\mathrm{a} \\
\mathrm{A}\end{array}$ & 14.72 & 1.70 & $\begin{array}{l}\mathrm{a} \\
\mathrm{A}\end{array}$ & 14.84 & $1.34 \mathrm{~A}$ & 14.60 & $1.38 \mathrm{~A}$ & 14.88 & 1.56 & $\stackrel{a}{A}$ & $15 \cdot 69$ & $2.02 \underset{A}{a}$ & a 15.02 & $2 \cdot 24$ & $\underset{\mathrm{A}, \mathrm{c}}{\mathrm{b}}$ & 14.96 & $\begin{array}{ll}1.97 \mathrm{C} \\
\mathrm{A}\end{array}$ & $\begin{array}{ll}c & 14.87 \\
A\end{array}$ & 2.03 & $\stackrel{\mathrm{b}, \mathrm{c}}{\mathrm{A}}$ \\
\hline $\begin{array}{l}\text { Nutritional } \\
\text { knowledge }\end{array}$ & 4.24 & 3.94 & 4.47 & 4.13 & 3.84 & $4 \cdot 10$ & & 4.37 & 4.19 & & 3.50 & 4.11 & & 4.46 & 3.99 & 4.04 & 5.02 & 3.92 & 4.07 & & $4 \cdot 30$ & 3.83 & 3.91 & 4.70 & & $4 \cdot 19$ & 4.18 & 3.89 & 3.81 & \\
\hline Healthy food intake & 3.26 & $0.34 \mathrm{~b}$ & 3.43 & $0.26 \mathrm{a}$ & 3.36 & 0.32 & $a, b$ & 3.38 & 0.33 & $a, b$ & 3.17 & 0.41 & $a, b$ & $3 \cdot 20$ & $0.39 \mathrm{a}$ & 3.06 & $0.46 \mathrm{~b}$ & 3.09 & 0.39 & $a, b$ & 3.14 & $0.48 \mathrm{a}$ & 3.13 & 0.39 & $\mathrm{a}$ & 3.13 & $0.42 \mathrm{a}$ & 3.13 & 0.50 & a \\
\hline $\begin{array}{l}\text { Unhealthy food intake } \\
\text { Inductive feeding strategies } \\
\text { Coercive feeding strategies }\end{array}$ & $\begin{array}{r}1.70 \\
23 \cdot 16 \\
24.89\end{array}$ & $\begin{array}{l}0.50 \\
3.40 \\
6.25\end{array}$ & $\begin{array}{r}1.57 \\
24.13 \\
23.90\end{array}$ & $\begin{array}{l}0.40 \\
3.84 \\
6.31\end{array}$ & $\begin{array}{r}1.61 \\
23.05 \\
23.40\end{array}$ & $\begin{array}{l}0.39 \\
3.38 \\
6.60\end{array}$ & & $\begin{array}{r}1.64 \\
22.87 \\
23.16\end{array}$ & $\begin{array}{l}0.37 \\
3.99 \\
6.47\end{array}$ & & $\begin{array}{r}1.69 \\
22.67 \\
25.42\end{array}$ & $\begin{array}{l}0.48 \\
3.49 \\
5.85\end{array}$ & & $\begin{array}{r}1.71 \\
22.88 \\
24.58\end{array}$ & $\begin{array}{l}0.40 \\
3.69 \\
5.50\end{array}$ & $\begin{array}{r}1.63 \\
21.17 \\
24.29\end{array}$ & $\begin{array}{l}0.40 \\
3.67 \\
6.52\end{array}$ & $\begin{array}{r}1.58 \\
21.92 \\
23.25\end{array}$ & $\begin{array}{l}0.47 \\
3.01 \\
6.15\end{array}$ & & $\begin{array}{r}1.71 \\
22.88 \\
24.78\end{array}$ & $\begin{array}{l}0.39 \\
3.35 \\
6.18\end{array}$ & $\begin{array}{r}1.70 \\
22.75 \\
23.10\end{array}$ & $\begin{array}{l}0.39 \\
3.75 \\
6.17\end{array}$ & & $\begin{array}{r}1.67 \\
22.56 \\
23.02\end{array}$ & $\begin{array}{l}0.43 \\
4.01 \\
5.95\end{array}$ & $\begin{array}{r}1.69 \\
22.25 \\
22.55\end{array}$ & $\begin{array}{l}0.39 \\
3.32 \\
6.16\end{array}$ & \\
\hline & $n$ & $\%$ & $n$ & $\%$ & $n$ & $\%$ & & $n$ & $\%$ & & $n$ & $\%$ & & $n$ & $\%$ & $n$ & $\%$ & $n$ & $\%$ & & $n$ & $\%$ & $n$ & $\%$ & & $n$ & $\%$ & $n$ & $\%$ & \\
\hline $\begin{array}{l}\text { Correct perception of } \\
\text { child's weight }\end{array}$ & 28 & 73.7 & 25 & $65 \cdot 8$ & 26 & 68.4 & & 26 & 68.42 & & 15 & 57.7 & & 16 & 61.5 & 15 & 57.7 & 17 & 65.4 & & 32 & $59 \cdot 3$ & 35 & 64.8 & & 39 & $72 \cdot 2$ & 32 & $59 \cdot 3$ & \\
\hline
\end{tabular}

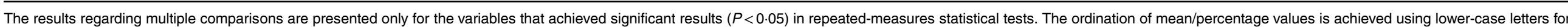

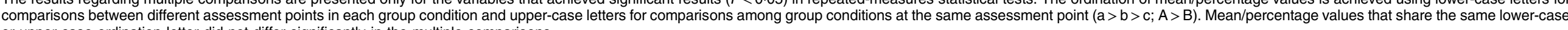
or upper-case ordination letter did not differ significantly in the multiple comparisons. 
The 'Red Apple' intervention (CIG) was the only condition that led to an improvement in children's healthy food intake after the intervention, although this difference became non-significant in the follow-up assessments. Nevertheless, the CIG maintained significant positive differences at those assessment points compared with the MIG and the CG. These results are especially important since the mean scores for this variable were already relatively high at baseline (on average, children consumed healthy foods more than 3-6 times per week). In contrast, the impact of the programme on children's unhealthy food intake was not noteworthy. Similar results were found after the HENRY (Health Exercise Nutrition for the Really Young) parent course ${ }^{(29)}$ where a significant improvement in fruit and vegetable intake was achieved for both children and parents, although the reduction in sugarsweetened foods and beverages was only found for parents. One possible explanation is that the children's consumption of unhealthy foods was already low before the intervention (the mean intake of unhealthy food was less than 1-2 times per week). A Portuguese study that assessed dietary habits of 4-year-old children showed that $65 \%$ of the sample consumed cakes and sweets at least once daily, and $52 \%$ had sodas and soft drinks daily ${ }^{(36)}$. Although the measures used were not completely equivalent, it is possible that our sample had better values for this food group from before the intervention, thus creating a floor effect. However, these results might also indicate that it is easier to promote healthy eating behaviours than to decrease unhealthy eating behaviours. Forthcoming interventions may need to direct more attention to parents' beliefs and behaviours related to the control of unhealthy foods.

Although children's eating is measured differently in the literature (e.g. through the use of different instruments and timings of assessment), thus making outcome comparisons between studies difficult ${ }^{(17)}$, we may conclude that, in general, a positive and long-lasting impact of parental interventions on children's eating patterns is not common $^{(15,17,21)}$, especially with brief interventions ${ }^{(21)}$. Although the results obtained are modest, the changes in the CIG suggest preliminary evidence for the effectiveness of the strategies used. For instance, features of the 'Red Apple' intervention, such as suggesting specific practices according to the developmental competencies of pre-school children (e.g. the most adequate ways to talk with young children about food, recognition of the child's ability to self-regulate the food intake through satiety cues), are relatively new in the way they are presented to parents. Future studies involving children with high-risk eating habits, as well as more sessions in the programme, are needed to confirm the effectiveness of this approach.

Regarding parental feeding strategies, the programme was not able to promote positive changes. This finding can be explained by the low dosage of the intervention, since only two sessions were dedicated to this issue. However, several tasks were proposed for parents to practice at home. In general, parents accomplished those tasks according to their specific problems (e.g. introduction of new and healthy foods for children with a less diversified diet, the 'belly training' for children who consumed higher portions of food), thus showing that these tasks were acceptable and pertinent. Earlier studies showed mixed results regarding changes in specific parental feeding practices after an intervention. In two programmes that also involved a brief educational intervention ${ }^{(37,38)}$, no significant differences were found. In contrast, a decrease in restrictive feeding practices was achieved after HarveyBerino and Rourke's intervention, which included sixteen one-hour weekly home visits ${ }^{(39)}$, as well as a study by West et al. which included a 12-week intervention group plus phone call sessions ${ }^{(40)}$. Both interventions were longer, more intensive and used individual coaching and feedback.

Nevertheless, the 'Red Apple' intervention was successful in the maintenance of parents' self-efficacy to regulate their children's eating behaviours towards a healthy diet. In fact, we found a significant decrease in parental self-efficacy for the CG but not for the intervention groups. As children grow, their eating behaviour becomes more difficult to control and they are more assertive in imposing their food likes and dislikes. Campbell et al.'s early work suggests that mothers' self-efficacy regarding the limitation of non-core foods/drinks may decline during the first years of a child's life ${ }^{(22)}$. As such, it is possible that the intervention might have had a protective effect against this parental self-efficacy decline. Earlier studies found a significant increase in parents' confidence in eliciting their children's compliance with a healthy diet, to encourage good behaviour towards food and to set limits after the intervention, but the absence of a control group did not allow for further detailed comparisons $^{(29,41)}$. Another study, which involved a Group Lifestyle Triple P intervention, found an increase in selfefficacy at 1-year follow-up, but the intervention was much longer and directed exclusively towards overweight children ${ }^{(40)}$. Two other studies did not find improvements in parents' self-efficacy ${ }^{(37,39)}$.

An unexpected result was the absence of significant findings for nutritional knowledge in the intervention groups. Earlier intervention studies showed an increase in parental nutritional knowledge ${ }^{(37,42)}$. Parents in the CIG, despite not improving their nutritional knowledge, were able to make the changes necessary for their children to increase their healthy eating behaviours. It is possible that these parents already had a minimum level of knowledge necessary to change their behaviours.

Additionally, the results on parental perceptions of children's weight did not confirm our initial hypothesis. Previous literature has emphasized that nutrition education programmes that include screening of children's BMI and feedback to parents can contribute to earlier awareness of children's weight patterns and active engagement 
in the adoption of healthier eating habits ${ }^{(34,43-45)}$. Furthermore, in our programme, we tried to overcome some barriers to the correct identification of children's weight status by parents, such as the understanding of the child's growth charts and percentiles ${ }^{(46)}$. However, it is possible that the time spent in this intervention or the group approach used was insufficient for parents to acquire the ability to observe the initial signs of weight problems and adjust their perceptions of the children's development. Further studies might consider the additional participation of a physician or a nurse in the programme to address the information about how to calculate the children's BMI and percentiles and to assess the risks to the children's health associated with their nutritional status. An early study found that parental recall of physicians' warnings about children's overweight are highly correlated with parental concerns about their children's weight, increasing up to six times their probability of being concerned ${ }^{(30)}$.

It is important to notice that although the 'Red Apple' programme was developed and designed for a universal and group application, the general objectives of the sessions may not fully match the needs of all participants. For some parents, it may be necessary to enhance the perception of risk regarding overweight or unhealthy eating habits; for others, it might be more important to provide strategies to regulate the child's defiant behaviour during mealtimes (asking for more food, refusing vegetables). This might be especially relevant in clinical samples, where parents and children could have specific issues to address during the intervention ${ }^{(47,48)}$. As such, the way the programme is built also allows its extension, combining group sessions with an individual component, or introducing booster sessions to reinforce changes. Moreover, the 'Red Apple' programme, although not currently applied, is manualized and available to be disseminated in kindergartens.

\section{Limitations}

The difficulty in maintaining reasonable rates of adherence throughout the programme was a major problem in the present study, although this issue was also frequent in other studies involving preventive programmes and extended follow-up assessments ${ }^{(49)}$. Considering the parents' reasons for non-attendance, it could be important that future studies offer additional solutions to overcome these barriers (e.g. offering childcare during the session, sessions in the morning or in the evening). The use of technologies to deliver some programme components and offer individual feedback ${ }^{(50,51)}$ might result in lower attrition. In our sample, parents with lower education levels dropped out more often in both intervention groups. Although these parents may be more focused on other priorities, additional efforts must be made to understand families' expectations about these programmes and to identify and overcome the barriers to change.

It is also possible that the small sample retained until the end of the study might have limited the statistical power of the analyses conducted. Additionally, in our sample, most of the parents had a college education, which could be less representative of the Portuguese population, and thus limit the generalizability of the results. Also, the results may not be replicable with children with unhealthier eating behaviours or with parents less motivated to participate. Further investigations with larger and/or clinical samples are needed to confirm the results obtained.

Given that the results were assessed only through parental report, it is important to consider the potential bias of reporting positive outcome data ${ }^{(15)}$, especially in the intervention conditions, in which parental involvement and contact with the research team were higher (e.g. social desirability and expectations), although this positive bias in the intervention groups was not observed across all dimensions.

\section{Conclusions}

In summary, the 'Red Apple' programme proved to be effective in the improvement of children's healthy food intake compared with a single nutrition educational session and a control condition. Participation in an intervention condition might also prevent the decline of parental selfefficacy in promoting healthier food intake as their children grow older. The absence of significant results regarding other parental variables targeted in the 'Red Apple' intervention, in addition to problems with attrition, highlights the need to optimize the strategies adopted (e.g. regarding session contents and methodologies, the dosage of the intervention) to augment the success of the programme.

\section{Acknowledgements}

Acknowledgements: The authors sincerely thank for their kind collaboration all the school boards and, especially, the parents, children and kindergarten teachers who were enrolled in the study. Financial support: This work was supported by the Faculty of Psychology, University of Lisbon (grant number BD/FPUL-052010). The funder had no role in the design, analysis or writing of this article. Conflict of interest: The authors declare that they have no conflicts of interest. Authorship: All authors participated in the literature research, conception and design of the study. A.I.G. performed the data collection. A.I.G., A.I.P. and M.S.R. carried out the statistical analysis, and together all authors interpreted and discussed the results. A.I.G. prepared the manuscript and all authors read, edited and approved the final version submitted for publication. Ethics of human subject participation: This study was conducted according to the guidelines laid down in the Declaration of Helsinki and all procedures involving human subjects were approved by the Research Ethics Committee of the Faculty of Psychology, University of Lisbon, and by the boards of all schools involved. Written informed consent was obtained 
from all parents. After receiving a brief explanation of the purposes of the study and the tasks involved, all children gave their verbal consent in the presence of the kindergarten teacher, which was formally recorded.

\section{References}

1. Rietmeijer-Mentink M, Paulis W, van Middelkoop M et al. (2013) Difference between parental perception and actual weight status of children: a systematic review. Matern Child Nutr 9, 3-22.

2. Ng M, Fleming T, Robinson M et al. (2014) Global, regional, and national prevalence of overweight and obesity in children and adults during 1980-2013: a systematic analysis for the Global Burden of Disease Study 2013. Lancet 384, 766-781.

3. Aparício G, Cunha M, Duarte J et al. (2013) Nutritional status in preschool children: current trends of mother's body perception and concerns. Aten Primaria 45, Espec Cong 1, 194-200.

4. Viveiro C, Brito S \& Moleiro P (2016) Pediatric overweight and obesity: the Portuguese reality. Rev Port Saude Publica 34, 30-37.

5. Wofford LG (2008) Systematic review of childhood obesity prevention. J Pediatr Nurs 23, 5-19.

6. Dietz W (1997) Periods of risk in childhood for the development of adult obesity: what do we need to learn? J Nutr $\mathbf{1 2 7}$, issue $9,1884 \mathrm{~S}-1886 \mathrm{~S}$.

7. Campbell M, Williams J, Hampton A et al. (2006) Maternal concern and perceptions of overweight in Australian preschool-aged children. Med J Aust 184, 274-277.

8. Birch LL \& Fisher J (1998) Development of eating behaviors among children and adolescents. Pediatrics 101, 539-549.

9. Birch LL (1998) Development of food acceptance patterns in the first years of life. Proc Nutr Soc 57, 617-624.

10. Manios Y, Grammatikaki E, Androutsos O et al. (2012) A systematic approach for the development of a kindergartenbased intervention for the prevention of obesity in preschool age children: the ToyBox-study. Obes Rev $\mathbf{1 3}$ Suppl. 1, 3-12.

11. Anzman S, Rollins B \& Birch L (2010) Parental influence on children's early eating environments and obesity risk: implications for prevention. Int $J$ Obes (Lond) 34, 1116-1124.

12. World Health Organization (2016) Report of the Commission on Ending Childhood Obesity. Geneva: WHO Press.

13. Brown T, Kelly S \& Summerbell C (2007) Prevention of obesity: a review of interventions. Obes Rev 8, Suppl. 1, 127-130.

14. Bluford D, Sherry B \& Scanlon K (2007) Interventions to prevent or treat obesity in preschool children: a review of evaluated programs. Obesity (Silver Spring) 15, 1356-1372.

15. Nixon C, Moore H, Douthwaite W et al. (2012) Identifying effective behavioural models and behaviour change strategies underpinning preschool and school-based obesity prevention interventions aimed at 4-6-year-olds: a systematic review. Obes Rev 13, Suppl. 1, 106-117.

16. Hesketh K \& Campbell K (2010) Interventions to prevent obesity in 0-5 year olds: an updated systematic review of the literature. Obesity (Silver Spring) 18, Suppl. 1, S27-S35.

17. Hingle M, O'Connor T, Dave J et al. (2010) Parental involvement in interventions to improve child dietary intake: a systematic review. Prev Med 51, 103-111.

18. Hendrie GA, Lease HJ, Bowen J et al. (2017) Strategies to increase children's vegetable intake in home and community settings: a systematic review of literature. Matern Child Nutr 13, 1-22.
19. World Health Organization (2016) Consideration of the Evidence on Childhood Obesity for the Commission on Ending Childhood Obesity: Report of the Ad hoc Working Group on Science and Evidence for Ending Childhood Obesity. Geneva: WHO Press.

20. Skouteris H, McCabe M, Swinburn B et al. (2011) Parental influence and obesity prevention in pre-schoolers: a systematic review of interventions. Obes Rev 12, 315-332.

21. Peters J, Sinn N, Campbell K et al. (2012) Parental influences on the diets of 2-5-year-old children: systematic review of interventions. Early Child Dev Care 182, 837-857.

22. Campbell K, Hesketh K, Silverii A et al. (2010) Maternal selfefficacy regarding children's eating and sedentary behaviours in the early years: associations with children's food intake and sedentary behaviours. Int J Pediat Obes 5, 501-508.

23. Warschburger P \& Kröller K (2012) Childhood overweight and obesity: maternal perceptions of the time for engaging in child weight management. BMC Public Health 12, 295.

24. Rhee K, DeLago C, Arscott-Mills T et al. (2005) Factors associated with parental readiness to make changes for overweight children. Pediatrics 116, e94-e101.

25. Morris H, Skouteris H, Edwards S et al. (2015) Obesity prevention interventions in early childhood education and care settings with parental involvement: a systematic review. Early Child Dev Care 185, 1283-1313.

26. Maynard M, Galuska D, Blanck H et al. (2003) Maternal perceptions of weight status of children. Pediatrics 111, 1226-1231.

27. Bandura A (2006) Guide for constructing self-efficacy scales. In Self-efficacy Beliefs of Adolescents, vol. 5, pp. 307-337 [F Pajares and T Urdan, editors]. Greenwich, CT: Information Age Publishing.

28. Vereecken C \& Maes L (2010) Young children's dietary habits and associations with the mothers' nutritional knowledge and attitudes. Appetite 54, 44-51.

29. Willis TA, George J, Hunt C et al. (2014) Combating child obesity: impact of HENRY on parenting and family lifestyle. Pediatr Obes 9, 339-350.

30. Gomes AI, Barros L \& Pereira AI (2017) Predictors of parental concerns about child weight in parents of healthy-weight and overweight 2-6 year olds. Appetite 108, 491-497.

31. Hughes S, Power T, Fisher JO et al. (2005) Revisiting a neglected construct: parenting styles in a child-feeding context. Appetite 44, 83-92.

32. Rogers RW (1983) Cognitive and physiological processes in fear appeals and attitude change: a revised theory of protection motivation. In Social Psychology: A Source Book, pp. 153-176 [JR Cacioppo and RE Petty, editors]. New York: Guilford Press.

33. Ajzen I (1985) From intention to actions: a theory of planned behavior. In Action-Control: From Cognition to Behavior, pp. 11-39 [J Kuhl and J Beckman, editors]. Heidelberg: Springer.

34. Moore L, Harris C \& Bradlyn A (2012) Exploring the relationship between parental concern and the management of childhood obesity. Matern Child Health J 16, 902-908.

35. Hildebrand DA \& Betts NM (2009) Assessment of stage of change, decisional balance, self-efficacy, and use of processes of change of low-income parents for increasing servings of fruits and vegetables to preschool-aged children. I Nutr Educ Behav 41, 110-119.

36. Lopes C, Oliveira A, Afonso L et al. (2014) Consumo alimentar e nutricional de crianças em idade pré-escolar: Resultados da coorte Geração 21 (Food and Nutritional Intake of Preschool Children: Results from the 21 Generation Cohort). Porto: Instituto de Saúde Pública da Universidade do Porto.

37. Horodynski MA \& Stommel M (2005) Nutrition education aimed at toddlers: an intervention study. Pediatr Nurs 31, 364-372. 
38. Shelton D, LeGros K, Norton L et al. (2007) Randomised controlled trial: a parent-based group education programme for overweight children. J Paediatr Child Health 43, 799-805.

39. Harvey-Berino J \& Rourke J (2003) Obesity prevention in preschool Native-American children: a pilot study using home visiting. Obes Res 11, 606-611.

40. West F, Sanders MR, Cleghorn GJ et al. (2010) Randomised clinical trial of a family-based lifestyle intervention for childhood obesity involving parents as the exclusive agents of change. Behav Res Ther 48, 1170-1179.

41. Harvey H \& Coleman G (2008) Raising healthy eaters: a parenting and nutrition curriculum. J Nutr Educ Behav 40, 52-53.

42. Haire-Joshu D, Elliott MB, Caito NM et al. (2008) High 5 for Kids: the impact of a home visiting program on fruit and vegetable intake of parents and their preschool children. Prev Med 47, 77-82.

43. Park M, Falconer C, Saxena S et al. (2013) Perceptions of health risk among parents of overweight children: a crosssectional study within a cohort. Prev Med 57, 55-59.

44. Crawford D, Timperio A, Telford A et al. (2006) Parental concerns about childhood obesity and the strategies employed to prevent unhealthy weight gain in children. Public Health Nutr 9, 889-895.
45. Jouret B, Ahluwalia N, Dupuy M et al. (2009) Prevention of overweight in preschool children: results of kindergartenbased interventions. Int J Obes (Lond) 33, 1075-1083.

46. Ben-Joseph E, Dowshen S \& Izenberg N (2009) Do parents understand growth charts? A national, internet-based survey. Pediatrics 124, 1100-1109.

47. Foster BA, Farragher J, Parker P et al. (2015) Treatment interventions for early childhood obesity: a systematic review. Acad Pediatr 15, 353-361.

48. Hoelscher DM, Kirk S, Ritchie L et al. (2013) Position of the Academy of Nutrition and Dietetics: interventions for the prevention and treatment of pediatric overweight and obesity. J Acad Nutr Diet 113, 1375-1394.

49. Skelton J \& Beech B (2011) Attrition in paediatric weight management: a review of the literature and new directions. Obes Rev 12, e273-e281.

50. Turner T, Spruijt-Metz D, Wen CKF et al. (2015) Prevention and treatment of pediatric obesity using mobile and wireless technologies: a systematic review. Pediatr Obes 10, 403-409.

51. Tate EB, Spruijt-Metz D, O'Reilly G et al. (2013) mHealth approaches to child obesity prevention: successes, unique challenges, and next directions. Transl Behav Med 3, 406-415. 